\title{
On the Need and Benefits of Waste Management in the Indian Context
}

\author{
Jerrin Thomas Panachakel \\ jerrin.panachakel@gmail.com.
}

\begin{abstract}
Waste management has gained importance in the recent days due to the awareness of environmental effects of improper waste disposal. Studies aimed at proper disposal of waste have come up with methods to tap the economic potential of proper waste management in addition to the scientific methods for waste disposal. This paper discusses about the need of a proper waste management system, especially for a country like India and about the financial benefit of the same.
\end{abstract}

Keywords-waste management, sustainable development

\section{INTRODUCTION}

In Hindu mythology, we see Devas and Asuras churning the sea to obtain the "nectar of immortality" or Amrit. They did succeed in obtaining the Amrit but with that, the "most vicious and venomous poison of universe", Halahala or Kalakuta was also created. Then, Lord Siva decided to drink the poison to prevent others from dying. Although Samudra Manthan is believed to have occurred centuries ago, it has fine but imperative links to the present.

Today, we see, in industries to households, intentional and unintentional creation of waste. Many water bodies in India have turned into dumpyards of many small and large scale industries. Approximately 960 million tones (MT) of solid waste was generated in India a decade back, of which 290 MT was from the industrial and the mining sector and 350 MT was from the agricultural sector [1]. Although these values may not alarming when we take into consideration the same parameters of other lower middle income group countries, the fact that the GDP contribution from the industrial sector has been increasing at a fast rate although the necessary technology for waster management and the awareness about the need for proper waste management is growing only at a snail pace is disturbing.

\section{INDUSTRIAL WASTE}

Waste or more precisely industrial waste is defined as those materials produced by an industrial activity and having the characteristic that the material is of no use for the specific industry [2]. They can be classified into two:

- Hazardous waste

- Non-hazardous waste

\section{A. Hazardous waste}

Though different agencies give different definitions for the term "Hazardous waste", in a broadsense they all refer to materials that can negatively affect human health or those materials which can deteriorate the environment, either alone or in contact with any other agent as "Hazardous waste".

Some examples of hazardous wastes are:

- Arsenic produced during mining.

- Mercury produced in chlor-alkali industries.

- Lead produced in lead acid battery smelters.

- Manganese produced in mining areas.

- Benzene in petrochemical industries.

\section{B. Non-hazardous waste}

Non-hazardous wastes are those materials which are non-toxic in nature, i.e.: they do not create any negative effect, either in the environment or human beings. Since these wastes are non-toxic, disposal of these wastes are easier when compared to hazardous waste since they do not require any special treatment.

\section{Waste Management}

\section{A. Why waste should be managed?}

Something that, in the first sight, contradicts with the very definition of waste is the need for proper waste management, because waste is defined as 
something that has no value. It cannot be farther from the truth to consider waste management to be a non-beneficial activity. There are many reasons for this, few of which are:

- Improper disposal of waste has a huge toll attached to it.

- Potential financial saving can be achieved if the raw materials wasted were not purchased in the first place.

- Profit, if the raw materials were converted to finished products rather than waste is lost. According to Richard Girling, on an average $90 \%$ of the raw material used in industries are wasted [3].

- The resources used for manufacturing are almost always limited, often a natural resource or an artificial resource derived from a natural resource. Reduction in tapping of these resources can help in sustained development.

\section{B. Waste Management Techniques}

The time tested and the most effective approach to waste management is "Reduce, Reuse and Recycle", often referred to as the " 3 Rs in waste management".

1) Reduce: Often in industries, raw-materials are purchased more than the optimum required quantity to make up for the loss of raw-material during transportation and storage or because the manufacturing process is not optimum and hence significant loss of raw materials can occur. What these industries forget is that the raw material used is limited and hence efforts should be taken to conserve it. For instance, a better storage equipments can increase the shelf-life of the raw-material.

In agricultural sector, the amount of water required can be reduced by replacing conventional irrigation systems with modern irrigation systems such as drip irrigation and by using modern farming methodologies such as SERI (The System of Rice Intensification).

2) Reuse: It is estimated that $80 \%$ of the goods manufactured are disposed within six months of their first use [3]. There are two demerits in this "one-time-use" approach:

1) The resources that have gone into the manufacturing cycle for manufacturing the product have not been utilized completely.
2) Economically feasible and environmentally friendly method for disposing off the waste thus generated may not be available.

3) Recycle: Many industries follow a linear economy model where raw materials are procured, used and the product is disposed after the product has served its primary purpose. This economy model creates a huge pressure on the scarce resources we have and is highly inefficient in terms on resource utilization. An alternate to the linear economy model is the circular economy model.

The goal of circular economy model is not merely reducing waste but to have changes in the industrial process or have new industries that can be fed with the wastes from another industry. These downstream industries are technologically as well as economically challenging.

Globally, there are many success stories of circular economy model. For instance, Petrleo Brasileiro S.A. - Petrobras, a multinational corporation in the petroleum industry in Brazil was faced with the challenge of disposing off in an economically and environmentally acceptable way the waste gravel generated from drilling operations. The solution was recycling. From 2007 onwards, the waste gravel from Petrobras is used as a raw material in cement plants instead of natural clay. Between 2007 and 2011, 57\% of the supplies of natural clay required by cement industries was replaced with waste gravel. This not only solved the problem of disposing off the waste but also saved 1,50,000 tones of natural clay [4].

Not only inorganic waste but organic waste too can be recycled and used for useful purposed. Some mostly untapped potential in this area are:

- Sugar molasses produced in sugar industry can be fermented for ethanol synthesis.

- Starch materials and peels in sago industry can be subjected to biomethanation for producing biogas.

In an agrarian economy like India, reclamation of water in the agricultural sector and the domestic has both short-term and long-term benefits [5], [6].

\section{Conclusion}

There is a huge untapped potential lying in waste management. This potential is underutilized primary because many are unaware of the benefits of proper 
waste management and also because of the lack of technology. Certifications like ISO 14001, C2C etc can help in creating awareness about the global trend in waste management. Incentives for conforming to this standards will motivate industries to implement state-of-the-art waste management systems.

\section{REFERENCES}

[1] A. Pappu, M. Saxena, and S. R. Asolekar, "Solid wastes generation in india and their recycling potential in building materials," Building and Environment, vol. 42, no. 6, pp. 2311-2320, 2007.

[2] B. Mansouri and B. Shahmoradi, "Pollution: Treating environmental toxins," J Adv Environ Health Res, vol. 2, no. 1, pp. 63-4, 2014.
[3] R. Girling, Rubbish!: Dirt on Our Hands and Crisis Ahead. Random House, 2011.

[4] WBCSD, "The cement industry creating solutions for safe, resource-efficient waste management," Cement Sustainability Initiative (CSI), 2009.

[5] PWC, "Closing the water loop: Reuse of treated wastewater in urban india," Knowledge paper, 2016.

[6] J. Christian-Smith, P. H. Gleick, N. Ross, L. Allen, M. J. Cohen, P. Schulte, and C. Smith, "California farm water success stories," Oakland, California: Pacific Institute. Retrieved on May, vol. 30, p. 2011, 2010. 